\title{
The Temporary Construction of Consumer Attitudes
}

\author{
Americus Reed II \\ The Wharton School \\ University of Pennsylvania \\ David B. Wooten \\ Marketing Department \\ University of Michigan \\ Lisa E. Bolton \\ The Wharton School \\ University of Pennsylvania
}

\begin{abstract}
This article investigates factors that affect whether people will construct attitudes based on external information from others, their own direct experience, or some combination of the two. Evidence from two studies suggests that consumers' salient goals and the order and degree of favorability associated with the two types of information (external vs. experiential) are factors that may jointly determine attitude construction. In study 1, participants who were in an evaluative (nonevaluative) frame of mind were more likely to construct their attitudes based on initial (recent) diagnostic information regarding the attitude object (i.e., an advertisement). Participants appear to use an anchoring and adjustment process to construct their attitudes. In study 2. to further test this anchoring and adjustment explanation, we use the well-established finding that people sometimes express attitude behaviors in line with a third party's views. When a third party created an external contingency, participants no longer systematically anchored on prior or recent information toward the attitude object. The results of these two studies point out the usefulness of identifying (a) processes of attitude construction, and (b) processes of how consumers determine whether a generated attitude is an appropriate guide for their behavior. The findings are discussed in terms of the current retrieval versus construction debate in the attitude literature.
\end{abstract}

Some attitude research appears to be based on the assumption that people walk around with stored attitudes toward some objects. In fact, the classic and more recent definitions of an attitude (e.g., a predisposed tendency to respond to something in a favorable way; Eagly \& Chaiken, 1993) reflect this premise, as does work demonstrating the functional usefulness of possessing a particular state of readiness to respond to classes of objects (Katz, 1960; Shavitt, 1990; Smith Bruner \& White, 1956). Therefore, some attitudes are quite stable and resistant to change (see Bennett, 1975; Bishop, Hamilton, \& McConahay, 1980; Brown, 1970, for a discussion on the stability of political attitudes).

Requests for reprints should be sent to Americus Reed II, Wharton School of the University of Pennsylvania, Marketing Department, 3620 Locust Walk, 1400 Steinberg Hall-Dietrich Hall, Philadelphia, PA 19104-6371. E-mail: amreed@wharton.upenn.edu
However, given cognitive capacity limitations, people probably do not have stored attitudes toward the infinite number of objects in their social world. In fact, a more contemporary school of thought has conceptualized (some types of) attitudes as temporary constructions (Schwarz \& Bohner, 2000; Tesser, 1978; Tourangeau \& Rasinski, 1988; Wilson \& Hodges, 1992; Wyer \& Hartwick, 1980; Zanna, 1990; Zanna \& Rempel, 1988). According to this constructionist viewpoint, (Bettman, Luce, \& Payne 1998; Feldman \& Lynch, 1988; Schwartz, 1978; Tourangeau \& Rasinski, 1988), an attitude is likely to be heavily influenced by the accessibility and salience of whatever attitude-relevant information comes to mind when an attitude is called for. In this view, attitudes that are not directly retrieved from memory (Fazio, Chen, McDonel, \& Sherman, 1982) might be the result of a dynamic, construction process in which "there is not a single attitude toward an object, but rather any number of attitudes depending on the number of different schemas available for thinking about the object" (Tesser, 1978, pp. 297-298). 
The focus of this article is on the interplay of two particular schemas that may lead to attitude formation. An attitude object can be thought of in terms of external information about the object. ' An attitude object can also be thought of in terms of a person's direct experience with the object (Regan \& Fazio, 1977). When attitudes are constructed, these two inputs-external information from others and one's own direct experience-can be combined in predictable ways to form an evaluation of a novel object. Attitude construction should depend on at least two factors: (a) salient goals that affect the accessibility of external or experiential information when an attitude is called for, and (b) the relative diagnosticity (valence) of the information to the impending judgment (Feldman \& Lynch, 1988). Based on these two assertions, the purpose of this article is to formally test the attitude construction process. The rest of this article is organized as follows. Two key aspects of the attitude literature are briefly discussed: (a) external informational influence, and (b) direct experience. Two studies are then presented that demonstrate the fluidness of attitude construction and how attitudes toward the same object can significantly shift depending on retrieval factors that affect the accessibility and diagnosticity of alternative inputs (external information and direct experience).

\section{TWO ALTERNATIVE SCHEMAS FOR ATTITUDE FORMATION}

\section{External Information}

A person can form an attitude based on external information from others. Obtaining factual evidence about an evaluated object has been described in the literature as informational influence (Kaplan \& Miller, 1987; Kelman, 1961; Park \& Lessig, 1977). For example, consider constructing an attitude toward tofu by reading about tofu in a cuisine magazine. How a person's attitude is influenced by this external information depends on many factors. Does the person have an accessible previous attitude toward tofu? Is it strong, weak, and so forth? Does the person have the ability or motivation to process the new information (Eagly \& Chaiken, 1993)? Therefore, it is thought that informational influence operates through a process of internalization (Kelman, 1961). That is, when information is internalized, it will not be accepted in toto but will be modified to fit the unique experiences of the target.

\section{Direct Experience}

A person can also form an attitude based on his or her own direct experience with the attitude object. Attitudes formed on the basis of direct experience with the attitude object are better predictors of behavior than are attitudes formed with-

\footnotetext{
'See Zanna and Rempel (1988) for the argument that attitudes can be based on affective, cognitive, or behavioral information.
}

out such experience (Regan \& Fazio, 1977; Songer-Nocks, 1976). For example, consider forming an attitude toward tofu by sampling tofu in a kiosk in the grocery store. It is thought that an attitude generated on the basis of direct experience is more likely to be salient (accessible) in memory, and hence generated very quickly (Fazio, Chen, McDonel, \& Sherman 1982; Fazio \& Zanna, 1978b) on subsequent exposure to cues related to the attitude object (e.g., seeing an ad for tofu burgers). This raises an interesting question: What moderates the relative use of alternative schemas that might impact the temporary construction of attitudes?

\section{MODERATORS OF SCHEMA IMPACT}

\section{Salient Goals and Accessibility}

Consider constructing an attitude based on two alternative schemas: (a) external information from others about the object; and (b) direct experience with the object. As prior research suggests, goals may influence the basis on which an attitude is formed (Bagozzi, Henderson, Dabholkar, \& Iacobucci 1996; Huffman \& Houston, 1993; King \& Balasubramanian, 1994; Lassiter, Geers, Apple, \& Beers, 2000; Petermen, 1997). For example, imagine two different consumers who have both first (a) read extensively about tofu and who then have (b) subsequently sampled tofu at the grocery store. Prior to reading about tofu, one of the consumers was about to embark on a new diet program; hence, this consumer is interested in evaluating possible consumption alternatives, including tofu. The other consumer had no such goal. Both consumers now find themselves in a situation in which they require an attitude to guide their behavior. How might these two consumers construct an attitude? Consider first the consumer whose goal or current concern (Klinger, 1975) during tofu exposure was specifically directed toward forming an eventual evaluation of tofu as a diet alternative. Because that goal was salient prior to both reading about the tofu and sampling it, the consumer might anchor on the initial information received regarding the object (e.g., article from the cuisine magazine) and adjust the attitude relative to direct experience with the object (e.g., sampling the tofu at the grocery store). In this example, the consumer's constructed attitude should reflect a primacy effect. Initial information will be more heavily weighted, and then adjusted for information considered later (i.e., the consumer's direct experience with the object.) Now consider the consumer with no such evaluative goal salient prior to being exposed to the tofu article in the cuisine magazine and sampling tofu in the grocery store. When an attitude toward tofu is later called for, this consumer may focus on information that is more easily retrievable from memory, given cognitive capacity limitations (Feldman \& Lynch, 1988; Wilson, Lindsey, \& Schooler, 2000). In this example, the consumer's constructed attitude reflects a recency effect inasmuch as the consumer anchors on the more recent information (sampling the tofu in the grocery store) and adjusts for the evaluative implications of the less recent external information that can be recalled (the article from the cuisine magazine). 
The Diagnosticity of External Information and Direct Experience

An attitude based on dircct experience is a custom-made attitude toward that specific attitude object. Fazio and Zanna (1978a, 1978b) emphasized the effect of direct experience on the confidence, certainty, and clarity with which the attitude is held. Presumably, the more confidence in an attitude or the more salient the attitude in memory, the more likely it is that the attitude can and will be acted on. However, sometimes direct experience is not enough. If an evaluation of an object based on direct experience lacks sufficient clarity to inform the person about the object, then forming an attitude based on the objective reality of direct experience becomes difficult (Ha \& Hoch, 1989; Hoch \& $\mathrm{Ha}, 1986)$. In these cases, a person may rely on the social reality of external information from others. Therefore, the extent to which a consumer relies on one basis for attitude construction versus another depends on the diagnosticity of each input when a judgment is called for (Feldman \& Lynch, 1988).

\section{Theoretical Summary and Hypotheses}

The relative impact of external information from others and a person's own direct experience with an attitude object on the temporary construction of attitudes should depend on at least two factors: (a) the salient evaluative goals of the individual, and, (b) any differential evaluative implications of thinking about the object in terms of external information from others or direct experience with the object. When people's thoughts and attention are focused on forming an attitude, then information will be processed as it is encountered. Thus, an attitude might be formed based on initial information and then adjusted for subsequent information (Tversky \& Kahneman, 1974). When people need to come up with an attitude on the spot, they may seek to retrieve the most easily accessible and diagnostic information relative to the judgment from memory (Feldman \& Lynch, 1988). Thus, in this case, an attitude will be formed based on the most recent information. This line of reasoning leads to the following two hypotheses.

H1: When consumers are in an evaluative (nonevaluative) state of mind, they will construct attitudes by focusing more on initial (recent) information schemas that they encounter(ed).

H2: The relative diagnosticity (i.e., valence) of each schema will moderate the impact of external information and direct experience on judgment.

\section{STUDY 1}

\section{Purpose of the Study}

The purpose of study 1 is to examine the impact of salient evaluative goals on the accessibility of inputs (external infor- mation from others and direct experience) and its subsequent impact on attitude construction. In study 1 , the focal attitude object was an advertisement, not an actual brand or product. This was done to maximize the likelihood of attitude construction (i.e., making sure that participants did not have preexisting attitudes to retrieve).

\section{Overview of Study 1}

In this study, participants constructed attitudes toward the advertisement with two possible schemas available: (a) external information from others about the advertisement, and (b) direct experience with the advertisement. Specifically, participants were exposed to external information from others about the object (via learning about others' ratings of the advertisement) and also directly experienced the object (via exposure to the actual advertisement). ${ }^{2}$

The two different bases for attitude construction had different implications for judgment based on design of the stimulus materials. Direct experience of the advertisement was pretested and designed to be relatively neutral (approximately 4 on a 1 to 7 scale). ${ }^{3}$ The external information was designed to be either very positive or very negative (to be described later). Based on our hypotheses, the temporary construction of attitudes based on this valenced external information from others and neutral direct experience will be a combination of these inputs (as illustrated in Figure $I$ and explained more fully later).

In study 1, we also manipulated the salience of goals by putting participants into an evaluative frame of mind (or not). We did this by having participants make either online (evaluative) or delayed (nonevaluative) judgments (Hastie \& Park, 1986). We also varied the order in which participants were exposed to the two different pieces of information (external information about the advertisement and direct experience with the advertisement) to demonstrate the efficacy of the salient goal manipulation and to show the differential impact of each schema on the temporary construction of participants' attitudes.

Specifically, when the salient goal is evaluative (i.e., the person focuses on forming an attitude), initial information will have a greater impact on judgment than subsequent infor-

\footnotetext{
${ }^{2}$ This research focuses on evaluations of the advertisement per se. Hence, direct experience with the ad occurs when consumers actually view the ad. If the focal object under consideration is the brand or actual product, then direct experience occurs when the consumer actually tries the brand or product. As one reviewer pointed out, this is reflected in extant literature where actual experience is contrasted with ad exposure.

"Thirty-two advertisements were randomly chosen from magazines judged to be familiar to and read by the participant pool. Participants were asked to use 7-point Likert-type scales to rate the 32 advertisements on seven dimensions of advertising appeal. These evaluations were made in the absence of any additional external information. Pretest results showed that nine ads were judged to be approximately neutral on a mean score of the seven dimensions. Three of these ads were chosen as stimulus replicates. See Figure 2 for the three ads used in both studies presented in this article.
} 


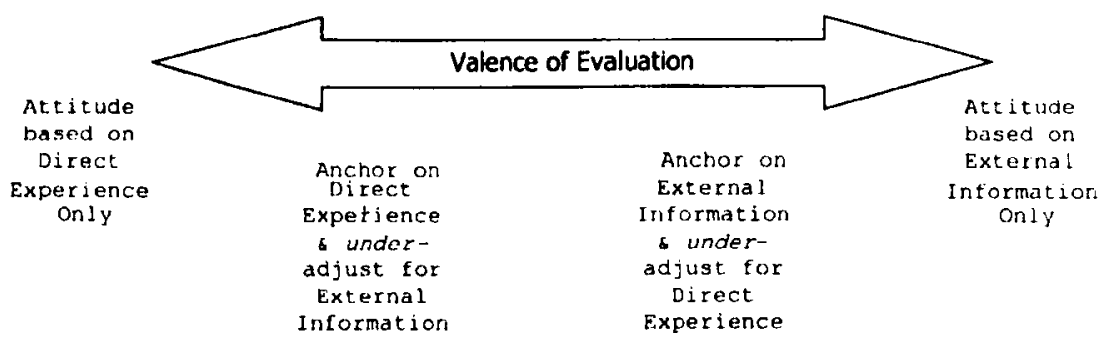

Note: Attitudes constructed via anchoring-and-adjustment vary when inputs (direct experience and external information) differ in valence.

FIGURE 1 Temporary construction of attitudes based on Direct experience (neutral) and external information (positive/negative).

ADI: Female Product

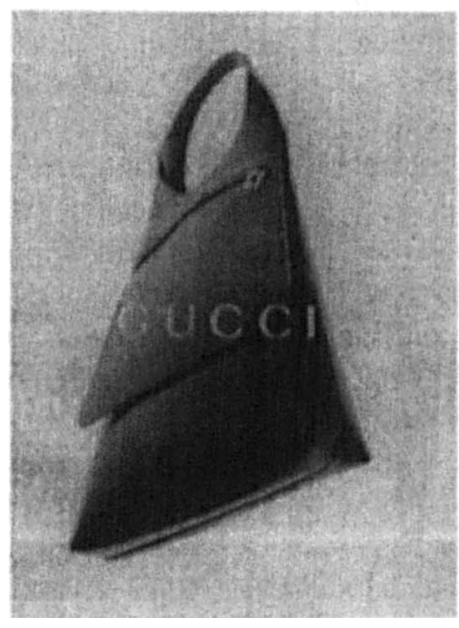

AD2: Male Product

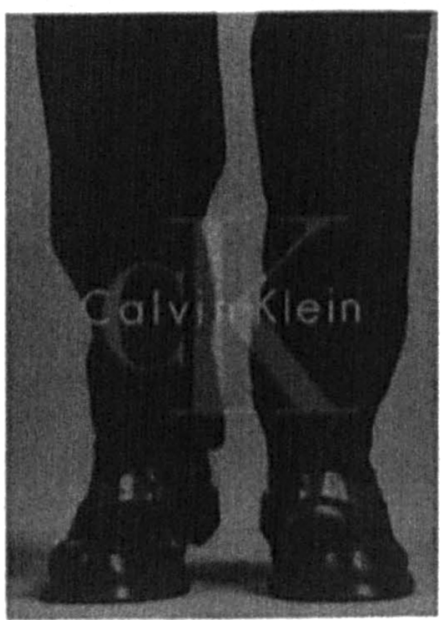

AD3: Gender Neutral Product

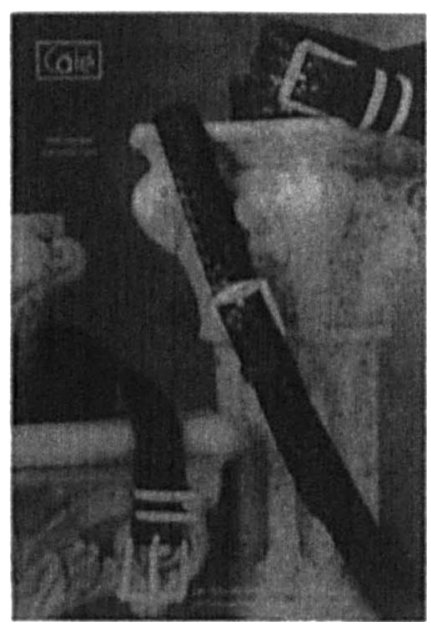

FIGURE 2 Experimental advertising stimulus replicates.

mation (a primacy order effect). When the salient goal is nonevaluative (i.e., does not involve forming an attitude), attitudes will be based on information in memory and recent information will have a greater impact than initial information (a recency order effect). The design of the stimulus materials permit us to test for these effects: judgments should be more extreme (either positive or negative) when participants focus more on external information from others (either positive or negative) rather than on their own direct experience (neutral).

\section{Method}

Participants and experimental design. Study 1 is a 2 (Order of Information) $\times 2$ (Valence) $\times 2$ (Goal) $\times 3$ (Stimulus Replicate) between-subjects design with three No-Influence control groups. A total of 273 undergraduate business school students from a major southeastern university participated in the study for extra credit.
Procedure. The cover story for this experiment asked participants to assess a market research portfolio. The information packet was a portfolio giving examples of the advertising firm's marketing research reports to be presented to potential clients. These reports included example data charts that depicted information and effectiveness ratings of the company's advertisements collected in past studies. Participants were urged to work through the packet at a brisk pace. On entering the lab for the experiment, participants were randomly assigned to experimental conditions.

Goal was manipulated such that participants either evaluated the advertisements (evaluative goal) or proofread the advertising material (nonevaluative goal). ${ }^{4}$ Participants in the

\footnotetext{
4 A proofreading goal was deemed sufficient to discourage participants from evaluating the ad (Park \& Hastak, 1994). Participants in the proofread. ing condition were later surprisingly asked to rate the advertisement in the
} 


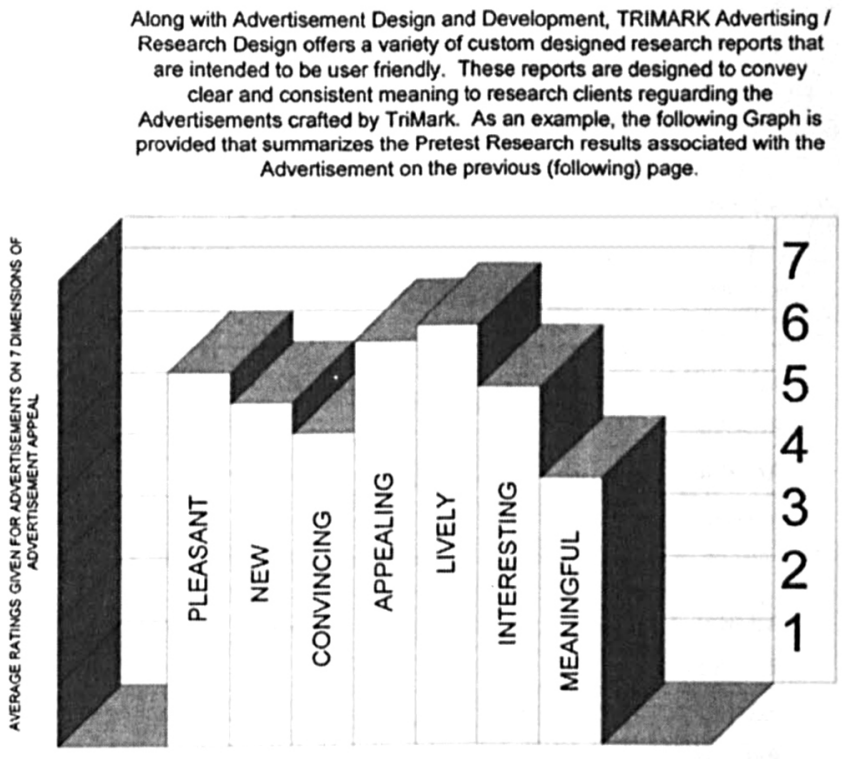

Exhibit 6. Results of Advertisement Evaluation Pre-Test Studies

This is an example of a 3-D Graph of research results. The samplo consisted of 125 individuals and

summarizes the

average rating given by each respondent

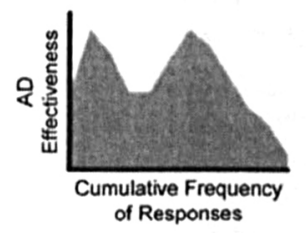

TriMark is dedicated to providing its clients with high quality, but simple and meaningful statistical and quantitative analyses that accompany Ads created and Tested by the company.

FIGURE 3 Example of positive external information manipulation.

evaluative condition were told ahead of time that they would rate an example advertisement designed by the advertising firm. Participants in the nonevaluative condition were told that they were to proofread the market research material. Participants saw one of three different ads in their portfolio materials (serving as Stimulus Replicates); these ads are illustrated in Figure 2.

Because the focal attitude object under consideration was the advertisement, participants' subjective experience of a full size color copy of the actual advertisement provided in the packet constituted direct experience with the advertisement. Secondhand information provided in

market research portfolio. The solicitation of proofreading comments in the postexercise questionnaire was expected to lend credence to the proofreading goal manipulation in the context of the cover story. In addition, a brief rationale was provided to participants to explain the need for proofreading comments (i.e., to test to what extent they affect advertisement evaluations). the form of market research data that had already been collected during prior research by the pseudo advertising firm constituted external information from others. Valence (i.e., diagnosticity) of this external information from others was manipulated as positive or negative via the distribution of other people's ratings depicted in the histogram chart. Figure 3 shows an example of the positive external information manipulation.

The ads themselves were pretested to be evaluatively neutral. In addition, the order of presentation was manipulated: participants either saw the advertisement followed by the external information from others (direct experience first) or saw the external information followed by the advertisement (external information first). After working through their packet, participants completed a postexercise questionnaire that gathered their proofreading comments and also measured their attitude toward the ad (pleasant, new, convincing, appealing, lively, interesting, and meaningful) on 1 to 7 scales. These dimensions were the dependent measure for study 1 . 
TABLE 1

Means and Standard Deviations for Study 1 Treatment and Control Groups

Treatment Conditions

\begin{tabular}{|c|c|c|c|c|c|}
\hline Salient Goal & Order & $\begin{array}{l}\text { Valence of Extermal } \\
\text { Information }\end{array}$ & $N$ & $M$ & $S D$ \\
\hline \multicolumn{6}{|l|}{ Ad 1} \\
\hline 1. Evaluative & Ad-Rat & $(+)$ & 12 & 4.58 & 0.47 \\
\hline 2. Evaluative & Rat-Ad & $(+)$ & 12 & 5.43 & 0.25 \\
\hline 3. Nonevaluative & Ad-Rat & $(t)$ & 12 & 5.71 & 0.20 \\
\hline 4. Nonevaluative & Rat-Ad & $(+)$ & 11 & 4.29 & 0.55 \\
\hline 5. Evaluative & Ad-Rat & $(-)$ & 10 & 4.54 & 0.52 \\
\hline 6. Evaluative & Rat-Ad & $(-)$ & 11 & 1.65 & 0.33 \\
\hline 7. Nonevaluative & Ad-Rat & $(-)$ & 10 & 2.70 & 0.39 \\
\hline 8. Nonevaluative & Rat-Ad & $(-)$ & 11 & 4.18 & 0.43 \\
\hline \multicolumn{6}{|l|}{ Ad 2} \\
\hline 1. Evaluative & Ad-Ral & $(+)$ & 11 & 4.40 & 0.46 \\
\hline 2. Evaluative & Rat-Ad & $(+)$ & 11 & 6.52 & 0.22 \\
\hline 3. Nonevaluative & Ad-Rat & $(+)$ & 11 & 5.38 & 0.33 \\
\hline 4. Nonevaluative & Rat-Ad & $(+)$ & 11 & 4.14 & 0.51 \\
\hline S. Evaluative & Ad-Rat & $(-)$ & 12 & 4.41 & 0.45 \\
\hline 6. Evaluative & Rat-Ad & $(-)$ & 12 & 2.75 & 0.33 \\
\hline 7. Nonevaluative & Ad-Rat & $(-)$ & 11 & 2.77 & 0.43 \\
\hline 8. Nonevaluative & Rat-Ad & $(-)$ & 11 & 3.82 & 0.53 \\
\hline \multicolumn{6}{|l|}{ Ad 3} \\
\hline 1. Evaluative & Ad-Rat & $(+)$ & 11 & 4.18 & 0.53 \\
\hline 2. Evaluative & Rat-Ad & $(+)$ & 11 & 5.68 & 0.24 \\
\hline 3. Nonevaluative & Ad-Rat & $(+)$ & 11 & 5.27 & 0.28 \\
\hline 4. Nonevaluative & Rat-Ad & $(+)$ & 11 & 4.13 & 0.54 \\
\hline 5. Evaluative & Ad-Rat & $(-)$ & 11 & 4.19 & 0.50 \\
\hline 6. Evaluative & Rat-Ad & $(-)$ & 16 & 2.69 & 0.38 \\
\hline 7. Nonevaluative & Ad-Rat & $(-)$ & 12 & 2.80 & 0.42 \\
\hline 8. Nonevaluative & Rat-Ad & $(-)$ & 11 & 4.09 & 0.51 \\
\hline \multicolumn{6}{|l|}{ Controls } \\
\hline AdI & & & & 3.81 & 0.51 \\
\hline Ad 2 & & & & 4.06 & 0.53 \\
\hline Ad 3 & & & & 4.21 & 0.44 \\
\hline
\end{tabular}

Note. Order refers to order of exposure to Ad (direct experience) and Ratings (external information from others); Rat = ratings. Means in bold are significantly different from their control group $(p<.05)$.

\section{Results}

An overall ad evaluation measure was constructed by averaging ratings on the measured dimensions (Cronbach coefficient alpha of 0.921 ). Mean evaluations of the advertisements as a function of experimental design factors are shown in Table 1. An analysis of variance (ANOVA) reveals a significant 3-way interaction of goal, order, and valence of information, $F(1$, $265)=625.42, p=.0001 .5$ Figure 4 shows a graph of the mean

'For ease of presentation, we have collapsed across the ad Stimulus Replicates. An analysis of variance including this factor revealed a 4-way interaction of Ad Stimulus Replicate, Goal, Order of Information, and Valence of evaluation of all the advertisements as a function of evaluative state (goal), order, and valence (diagnosticity) treatments. Follow-up analyses revealed the predicted effects on attitudes:

Extemal Information, $F(2,249)=2.92, p=.056$. However, the interaction with ad stimulus is theoretically uninteresting, merely reflecting differences in the impact of the ad stimuli. This is evident in the means for each ad stimulus that are reported in Table 1, and was confirmed by finding a similar 3-way interaction for each ad stimulus. Thus, our conclusions would not differ if this full analysis were reported and we can safely collapse across ad stimuli without lessening the conservatism of our hypothesis testing. As an added benefit, doing so also improves the clarity of exposition of our results. A more detailed breakdown of the analysis by ad stimulus is available from the authors. 


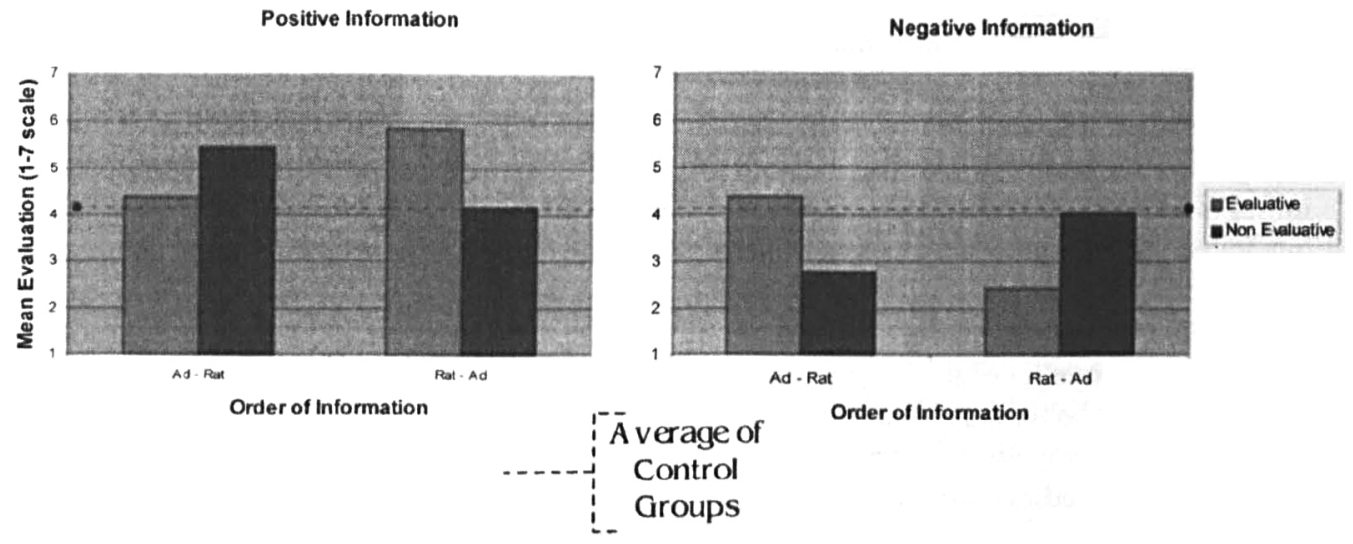

FIGURE 4 Mean attifudes toward the advertisements as a function of evaluative state, valence, and order information (Study 1).

When participants had an evaluative goal salient during stimulus exposure, the order and valence of information interacted, $F(1,136)=360.05, p=.0001$. When participants saw positive external information first, their judgments were more positive than when they experienced the relatively neutral ad first, $F(1,66)=138.58, p=.0001$. When participants saw negative external information first, their judgments were more negative than when they experienced the relatively neutral ad first, $F(1,70)=226.4, p=.0001$. When the salient goal was nonevaluative during stimulus exposure (i.e., proofreading conditions), the order and valence of information interacted and revealed the opposite pattern of results, $F(1,129)=$ $270.87, p=.0001$. When participants saw positive external information second, their judgments were more positive than when they experienced the relatively neutral ad second, $F(1$, $65)=145.80, p=.0001$. When participants saw negative external information second, their judgments were more negative than when they experienced the relatively neutral ad second, $F(1,64)=126.14, p=.0001$. Thus, a primacy effect was obtained under an evaluative goal and a recency effect was obtained under a nonevaluative goal. These results are consistent with the hypotheses.

An alternative analysis also supports our proposal that salient goals affect the relative impact of external information and direct experience on the construction of attitudes. Specifically, planned contrasts were conducted of the judgments of participants predicted to weight direct experience with the ad more (groups $1,4,5$, and 8 ) against the judgments of participants predicted to weight external information more heavily (i.e., positive external information for groups 2 and 3 and negative external information for groups 6 and 7). Means for these planned contrasts differed in the expected direction. Participants predicted to weight positive external information provided more positive judgments compared to participants predicted to weight direct experience more heavily, $F(1,270)=$
$337.11, p=.0001$. Similarly, participants predicted to weight negative external information more heavily provided more negative judgments compared to participants predicted to weight direct experience more heavily, $F(1,270)=490.88, p=$ .0001 . These results are also consistent with the hypotheses.

Overall, the pattern of means supports an explanation based on anchoring and adjustment. With an evaluative goal, participants anchor on initial information (either the relatively neutral ad itself or valenced external information from others) and then adjust for subsequent information (hence, a primacy effect). With a nonevaluative goal, participants anchor on more recent information recalled from memory and then adjust for information presented earlier (hence, a recency effect).

\section{Discussion}

Study 1 demonstrates how salient goals, valence, and order of information interact and influence attitude construction. An anchoring and underadjustment heuristic nicely predicts the temporary construction of attitudes in this study. That is, attitudes were more extreme when anchored on valenced external information from others and adjusted for relatively neutral direct experience. Conversely, attitudes were less extreme when anchored on relatively neutral direct experience and adjusted for valenced external information from others. The salient goal and order of information together determine the inputs on which attitudes are anchored and then adjusted. When an evaluative goal is salient during exposure to inputs, judgments are anchored on initial information (reflecting a primacy order effect). When a nonevaluative goal is salient, judgments are anchored on recent information (reflecting a recency effect). Interestingly, these results illustrate quite clearly the potential for fluctuation in attitudes that are temporarily constructed. 
Consider judgments made when an evaluative goal was salient. As study 1 demonstrated, direct experience had a greater impact when it preceded external information from others under an evaluative goal; in contrast, external information had a greater impact when it preceded direct experience under an evaluative goal. This finding provides evidence of how a person's initial direct experience appears to diminish the subsequent impact of others' opinions, whereas others' opinions appear to diminish the subsequent impact of a person's direct experience. For example, reading a thumbs-up movie review before seeing a mediocre movie may lead to more positive judgments of the movie than if one had viewed the movie first and then read the reviews. Similarly, negative word-of-mouth before seeing a mediocre movie might lead to more negative judgments of the movie than if the movie was viewed before hearing others' reviews. The movie situation is an example in which people seem very likely to have a salient evaluative goal.

However, for other attitude objects, people may be less likely to have a salient evaluative goal. For example, people may be exposed to information about a product before an attitude is required to guide behavior. However, when a later need arises to form a judgment based on memory, more recent information may be easier to retrieve and may receive greater weight in constructing an attitude (as was demonstrated in study 1). Such recent inputs to judgment may include either external information from others or direct experience with the attitude object. For example, my brother and his wife have purchased a new set of kitchen appliances. When I visit, I gain direct experience with their appliances and also hear their opinions of various brands, but I am not motivated to make my own judgment until I later encounter a need to do so when buying my own set of kitchen appliances. In this case, the opinion of my brother and his wife is likely to have greater weight on my judgment if it was more recently heard and therefore is more easily recalled than my own direct experience with appliances. (Of course, other factors also affect ease of retrieval; this example assumes ceteris paribus conditions.)

\section{THE TEMPORARY CONSTRUCTION OF ATTITUDES: A FURTHER TEST OF ANCHORING AND ADJUSTMENT}

The pattern of effects found in study 1 strongly argues for an anchoring and adjusiment explanation-which we believe is consistent with the idea of attitude construction and the interplay of the two bases for attitude formation examined in the study. To provide further evidence for temporary attitude construction based on direct experience and external information from others, we conducted a second study that employs a well-established phenomenon as a boundary condition on the attitude construction processes observed in study 1. Consider the earlier tofu example. Assume that a consumer forms a negative attitude toward tofu based on some combination of direct experience with the tofu along with external information. De- spite disliking tofu, this consumer may express a favorable attitude toward tofu to impress a new friend who likes tofu and serves it at a special dinner. This circumstance is an example of an external contingency that moderates attitude expression.

\section{Theoretical Summary and Hypotheses}

The notion that people express attitudes consistent with reward-mediating social referents is a well-established finding (Deutsch \& Gerard, 1955). Research on accountability (expecting to have to justify one's opinions to others) also suggests that people will conform to the views of others when suspected or known (Tetlock, Skitka, \& Boettger, 1989; for a more recent synthesis, see Lemer \& Tetlock, 1999). Considerable extant research informs us that attitudes that are generated can often be overridden by external contingencies. Kelman (1961) defined compliance-based processes of social influence as influence attempts that do not result in true attitude change. Compliance-driven processes have also been called normative influence or reward power (Deutsch \& Gerard, 1955; Fishbein \& Ajzen, 1975; French \& Raven, 1959). They are often the result of the expectations of how others will interpret an expressed attitude. Thus, the expectations of others can act as an external contingency that superficially guides behavior and affects the expression of temporarily-constructed attitudes.

We employ the aforementioned phenomenon to establish a boundary condition on the attitude construction process demonstrated in study 1 . We argue that participants construct temporary attitudes based on external information from others or direct experience, anchoring on the most salient information and adjusting for less salient information. However, as the tofu example illustrates, the expression of attitudes can also be influenced by an external contingency such as the expectations of others. If an expectation (e.g., the favorable attitude of another) is salient and indicates that a specific attitude (e.g., liking tofu) will lead to some favorable outcome (c.g., desired friendship), then this contingency may moderate the evaluative implications of attitudes that are constructed. In other words, the expression of an attitude will be moderated by the external contingency (i.e., the expectations of others). This leads to the following hypothesis.

H3: When participants are aware that a third party might reward them for having a certain attitude, they will no longer systematically anchor on prior or recent information toward the attitude object and adjust for diagnostic alternative inputs. Rather, participants will conform to the expected views of the third party when expressing attitudes.

\section{STUDY 2}

\section{Purpose of the Study}

The purpose of study 2 is to provide further evidence that participants indeed anchor on initial (recent) informational in- 
puts in an evaluative (nonevaluative) state and construct their attitudes via an anchoring and adjustment process that is moderated by the evaluative diagnosticity (valence) of external information and direct experience. We attempt to provide further evidence for the temporary construction of attitudes by relying on the well-established phenomenon that the expectation of others moderates attitude expression.

\section{Overview of Study 2}

Study 2 is a partial replication of study 1 but also includes an external contingency manipulation; that is, we manipulated participants' expectations of how others will interpret their attitudes. Half of the participants were led to believe that the marketing firm that is conducting the research may contact them. The logic of this manipulation relies on establishing an expectation derived from participants' desire to obtain rewards via a social relationship with the market research firm. Specifically, half of the participants believe that the market research firm will invite the use of participants' comments in a subsequent ad campaign on behalf of the firm in which the participants will be paid. As a result, participants expect that the market research firm will prefer to obtain favorable responses from participants. The major prediction of study 2 is that expectations driven by an external contingency (i.e., the financial reward from the marketing research firm) will affect the expression of their attitudes. In other words, the relative impact of external information from others and direct experience on the expression of attitudes should be moderated by this additional social influence component.

\section{Method}

Participants and experimental design. A total of 118 undergraduate business students from a major southeastern university were randomly assigned to conditions in a procedure and cover story that was similar to study 1 . The experiment is a 2 (External Contingency) $\times 2$ (Goal) $\times 2$ (Order of Information) $\times 1$ (Negative External Information Only) $\times 2$ (Stimulus Replicate) between subjects factorial design."

Procedure. As in the first study, participants were asked to assess a marketing research portfolio. Half of the participants were informed that it was highly likely that they might be contacted and compensated for the use of their comments by the company in future advertisement and market research presentations, thereby creating an External Contingency. After receiving this manipulation (or not), participants then worked through booklets containing the direct experience and external information. As in

\footnotetext{
${ }^{6}$ In study 2, we used two of the ads from study 1 . We have collapsed across ad stimulus when reporting our results. We also used only negative information from others given the logic of the external contingency manipulation.
}

study 1, goal was manipulated such that participants either evaluated the advertisements (evaluative goal) or proofread the advertising material (nonevaluative goal). Participants saw one of two different ads in their portfolio materials (serving as Stimulus Replicates). Order of information was manipulated: participants either saw the advertisement followed by the external information from others (direct experience first) or saw the external information followed by the advertisement (external information first). (As before, the ads were pretested to be evaluatively neutral. Only negative external information from others was used in this study.) After working through their packet, participants completed a postexercise questionnaire that gathered their proofreading comments and also measured their attitude toward the ad.

Manipulation checks. Participants were asked an administrative question that assessed the extent to which they would find it desirable to have their comments used in a future advertisement or rosearch portolio by the pseudoadvertising firm (on a 1-7 scale). Participants in the external contingency treatment groups were expocted to show a stronger desire to assess the advertising information in a more favorable way. ${ }^{7}$ Results showed that participants in the external contingency treatment groups rated it mone desirable to have their comments used than participants not receiving the external contin-

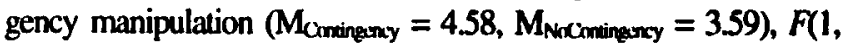
$115)=23.98, p<.0001$.

\section{Results}

An overall ad evaluation measure was constructed by averaging ratings on the measured dimensions (Cronbach coefficient alpha of 0.898 ). Mean evaluations of the advertisements as a function of experimental design factors are shown in Table 2 and Figure 5. An ANOVA of the experimental groups reveals a significant 3-way interaction of salient goal, order of information, and external contingency, $F(1,110)=30.74, \mathrm{p}=.0001$. Follow-up analyses revealed the following effects:

Under no external contingency, goal and order of information interacted as predicted, $F(1,55)=64.63, p=.0001$. When participants saw negative external information first with an evaluative goal, their judgments were more negative than when they experienced the relatively neutral ad first, $F(1,27)$ $=85.55, p=.0001$. When participants with a nonevaluative (proof reading) goal saw negative ratings information second, their memory-based judgments were expected to be more negative than when they experienced the relatively neutral ad second. Although in the expected direction, the mean difference was not significant, $F(1,28)=1.43, p=.243$. Under an external contingency, goal and order of information did not

\footnotetext{
'It is assumed that if participants indicated that it was desirable for them to have their comments used, they would be motivated to rate the stimuli more favorably because the participants would assume that the company would be more inclined to use favorable evaluations for testimonial purposes.
} 


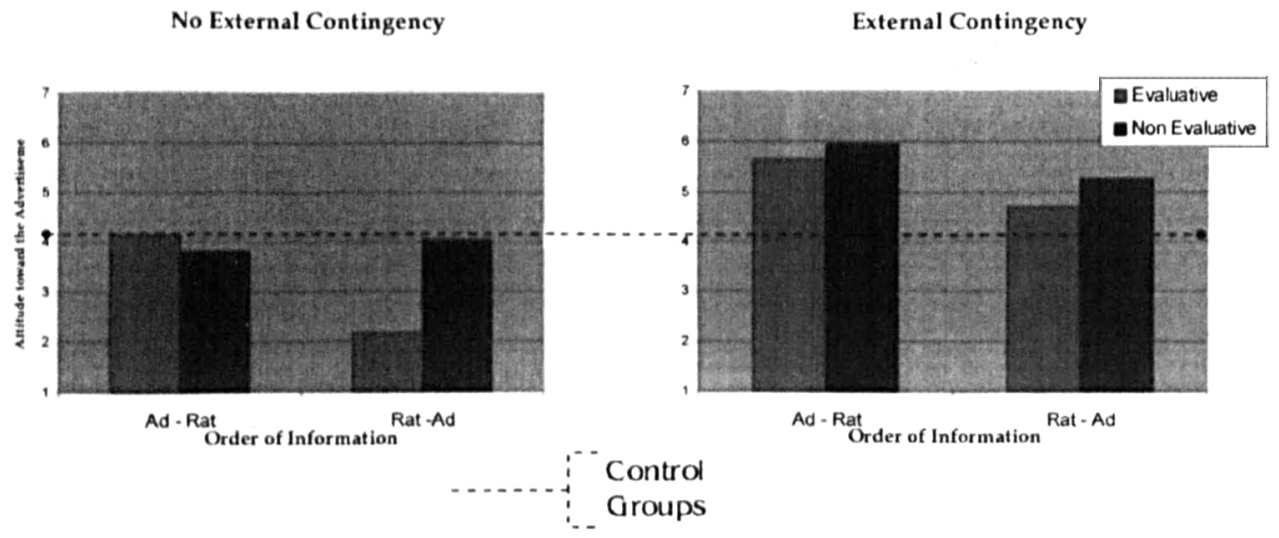

FIGURE 5 Mean attitudes toward the advertisements as a function of evaluative state, valence, and order information (Study 2).

TABLE 2

Means and Standard Deviations for Study 2 Treatment and Control Groups

Treatment and Conditions

\begin{tabular}{|c|c|c|c|c|c|}
\hline External Contingency & Salient Goal & Order & $N$ & $M$ & $S D$ \\
\hline 1. No Contingency & Evaluative & Ad-Rat & 15 & 4.14 & 0.53 \\
\hline 2. No Contingency & Evaluative & Rat-Ad & 14 & 2.17 & 0.62 \\
\hline 3. No Contingency & Nonevaluative & Ad-Rat & 15 & 3.84 & 0.63 \\
\hline 4. No Contingency & Nonevaluative & Rat-Ad & 15 & 4.04 & 0.16 \\
\hline 5. Contingency & Evaluative & Ad-Rat & 15 & 5.64 & 0.40 \\
\hline 6. Contingency & Evaluative & Rat-Ad & 14 & 4.69 & 0.33 \\
\hline 7. Contingency & Nonevaluative & Ad-Rat & 15 & 5.69 & 0.58 \\
\hline 8. Contingency & Nonevaluative & Ral-Ad & 15 & 5.27 & 0.44 \\
\hline 9. Control & & & & 4.14 & 0.44 \\
\hline
\end{tabular}

Note. Order refers to order of exposure to Ad (direct experience) and Ratings (external information from others); Rat = ratings. Means in bold are significantly different from the control $(p<.05)$.

significantly interact, $F(1,55)=1.45, p=.233 .^{8}$ All attitudes were significantly greater than neutral (all $p s<.001$ ) in the four treatment groups where there was an external contingency. Expressed attitudes were positive despite the fact that external information was negative and direct experience was neutral, reflecting the impact of the external contingency on evaluations.

\footnotetext{
"There was, however, a main effect of salient goal, $F(1,55)=17.11, p=$ .0001 , and onder of information, $F(1,55)=57.78, p=.0001$. Participants' judgments were less positive when made under an evaluative goal and when negative information from others preceded direct ad experience. Although no specific predictions were made for the order effect, the main effect of salient goal is consistent with our predictions.
}

An alternative analysis also supports the predictions of this study. Specifically, planned contrasts were performed on the judgments of participants predicted to more heavily weight their direct experience with the (neutral) ad (groups 1 and 4) against the judgments of participants predicted to more heavily weight (negative) external information (groups 2 and 3 ) and against the judgments of participants predicted to be affected by the (positive) external contingency (groups 5, 6, 7, and 8). Means for these planned contrasts differed in the expected direction. Participants predicted to rely more on external information provided more negative judgments compared to participants predicted to more heavily weight their direct experience with the ad, $F(1,115)=33.24, p=.0001$. Similarly, participants predicted to be affected by the external contingency provided more positive judgments compared to 
participants predicted to rely on their own direct experience, $F(1,115)=68.88, p=.0001$.

This is particularly striking because (what appeared to us to be) a relatively mild manipulation of an external contingency (advising participants that they might be contacted by the market research firm and receive some compensation for their opinions) had a strong (positive) impact on judgment, despite conflicting with other available information (negative external information or neutral direct experience) on which to construct and express an attitude.

\section{Discussion}

Overall, the results of study 2 are consistent with predictions. Varying the order of negative external information and neutral direct experience produces empirical results that are consistent with the anchoring-and-adjustment explanation posited in study 1. Participants combine direct experience and external information from others in forming evaluations. The relative influence on these inputs depends on their salience at the time of evaluation. Furthermore, an external contingency was also shown to influence the attitudes expressed by participants. This finding in and of itself is not new and it is not our purpose to demonstrate it. Rather, we believe that an additional test of the anchoring and adjustment explanation can be conducted by relying on the well-established finding in the social influence literature that people will express attitudes consistent with a reward-mediating third party. In fact, our predictions were confirmed by the data. When participants thought that a favorable attitude would gain some desirable outcome, they expressed such an attitude even when it conflicted with both the evaluative implications of external information from others and their own direct experience. This finding suggests that participants did not systematically anchor on prior or recent diagnostic information but rather rely on the evaluative implications of the external contingency in expressing an attitude. In other words, attitude expression was the result of a dynamic construction process based on salient informational inputs and moderated by external contingencies.

\section{GENERAL DISCUSSION AND LIMITATIONS}

Attitudes can be constructed in various ways (Schwarz \& Bohner, 2000). Two such bases for attitude formation are (a) external information from others about the attitude object, and (b) one's own direct experience with the object. In the current empirical work, evidence suggests that the salient processing goal and the evaluative implications of different schemas or bases on which to form attitudes affect the temporary construction of attitudes. In study 1 , attitudes are con- structed from direct experience and external information. Salient goals and order of information jointly influence attitude formation. Furthermore, this explanation was supported in study 2 . In the absence of an external contingency, goals, valence, and order of information influenced attitude construction and expression in a manner consistent with anchoring and adjustment. Study 2 also demonstrated that external contingencies (such as the expectations of others) can intervene between the construction and subsequent expression of attitudes based on external information and direct experience. Rewards and punishments linked to the consequences of behaviors can motivate people to express attitudes that gain a favorable reaction from others. Similarly, expecting to have to justify one's opinion to others (i.e., accountability to the marketing research firm) can also lead people to conform to the known or suspected views of others. The external contingency in study 2 (that participants may be contacted by the marketing research firm) seems to have motivated participants to express attitudes that were more favorable (i.e., in line with the firm's expectations).

Thus, external contingencies such as normative influence can affect behavior or expressed attitudes through a compliance-based process (Kelman, 1961) without affecting true, underlying attitudes. In contrast, an influence is internalized when a person perceives "others in the group as mediators of fact" (Burnkrant \& Cousineau, 1975, p. 207). Thus, informational influence occurs when external information (ratings from others) is used in forming an attitude (in combination with direct experience). Empirical results from study $I$ and the no-external-contingency groups in study 2 appear to reflect internalization during attitude construction, whereas the external-contingency groups in study 2 reflect compliance during attitude expression. Therefore, we take this combined pattern of results across these studies as convergent evidence for the anchoring and adjustment explanation of the temporary construction of consumer attitudes toward the advertisements and the moderation of subsequent attitude expression by external contingencies.

Although empirical results in this study support predictions, some limitations must be noted. Although the overall results of study 2 are supportive, there are two anomalous findings. First, we did not find the predicted simple effect of order when participants with a nonevaluative goal formed attitudes under no external contingency. Specifically, the mean (in cell 3 of Table 2) is not as negative as predicted if attitudes are being formed by anchoring on recent negative ratings information and underadjusting for earlier neutral direct experience. (Although it is directionally lower than neutral, the equivalent cell 7 means in study 1 were more negative.) Second, we did not predict the main effect of order of information in the presence of an external contingency. Taken together, these results could be interpreted as casting some doubt on the efficacy of our manipulation of salient evaluative goals. If participants spontaneously adopted an evaluative goal in the nonevaluative condition, this would reduce the likelihood of 
finding the predicted recency effect. It would also explain the main effect of order of information in the external contingency conditions. Indeed, the pattern of means is consistent with the notion that the impact of an external contingency on attitudes is at least somewhat constrained by direct experience and external information. Specifically, attitudes were less positive when negative information preceded the direct experience of neutral ad information than vice versa-perhaps because participants spontaneously tended to make judgments online so initial negative information pulled down attitudes. In addition, judgments were more positive when participants did not have an evaluative goal-perhaps because there is more room for biased interpretation of direct experience and external information recalled from memory (rather than stimulus based). Nonetheless, our prediction is supported: an external contingency in the form of expectations from others had direct effects on the construction of attitudes in a way that further supports the anchoring and adjustment explanation posed earlier.

\section{CONCLUSIONS AND FUTURE RESEARCH}

It seems reasonable to assume that we do not carry around attitudes toward the vast array of situated entities toward which judgments are needed. The fluidity of many of our attitudes is well-established (Bishop, 1987; Schwarz \& Bless, 1992; Wilson \& Hodges, 1992), thereby supporting the view that such evaluative judgments might be based on the most accessible and diagnostic information available to the individual at that time. The more extreme constructionist view holds that attitudes are no different from any other cognition and are constructed at that moment out of both accessible information and comparison frames, the latter sometimes producing assimilation or contrast effects (Bettman, Luce, \& Payne, 1998; Feldman \& Lynch, 1988; Schwartz, 1978; Schwarz, 2000; Tesser \& Martin, 1996; Tourangeau \& Rasinski, 1988). It is not surprising that some attitudes studied in the laboratory setting appear to be somewhat fluid because these expressions of attitude are likely to be ill-formed or weakly held to begin with. However, a constructionist viewpoint on attitudes does not necessarily imply that people do not have attitudes. People will have attitudes toward very important objects that they care about.

Our research is rooted in the notion that these conflicting viewpoints can be reconciled by examining the factors that influence attitude generation and retrieval. The studies in this article focus on several factors that influence attitude construction and expression. For example, in this article, we assumed that individuals can construct their attitudes based on relevant schemas, namely external information and direct experience. Fazio and his colleagues argued that, if a person forms a very negative attitude toward some object by experiencing that object, then this negative attitude will probably have more impact than a very negative attitude formed on the basis of simply reading about the object. We agree, but we suggest that this is only part of the story. People may access an attitude directly from memory (as Fazio's work points out), but if such an attitude is not available or accessible from memory, a person may construct an attitude on the spot (as is consistent with other theorizing in the attitude literature; Feldman \& Lynch, 1988; Lynch, Marmorstein, \& Weigold, 1988; Lynch \& Srull, 1982). We argue that the construction of this potentially temporary attitude will be based on salient evaluative information and examine two potential sources: external information and direct experience. Our results suggest that both external information and direct experience may serve as evaluative inputs in attitude construction--a finding consistent with Fazio's research and also Fishbein's expectancy-belief model of attitudes (Fishbein \& Ajzen, 1975). However, our research also takes into account the influence of goals and the valence and order of information exposure.

Salient evaluative or nonevaluative goals, valence, and order of information determine the relative influence of inputs in attitude construction. Moreover, an external contingency moderates the expression of constructed attitudes. If context-dependent activation leads to the expression of different attitudes, any individual might possess or at least have the potential to construct multiple context-dependent attitudes (Wilson \& Hodges, 1992). All of this implies that the concept of an attitude as a relatively long-lasting, stable mental representation might need to be reexamined (Schwarz \& Bohner, 2000). More generally, this raises the issue of whether judgments and behavior depend on the retrieval of abstract knowledge or on dynamically constructed combinations of individually retrieved episodes (Wilson et al., 2000). For example, Zanna and Rempel's (1988) model of attitudes suggested that attitudes can be based on cognitive information (as suggested by expectancy value approaches), affective information (attitudes formed through mere exposure or conditioning; Zajonc, 1968a), and behavioral reactions (such as attitudes formed on the basis of counterattitudinal actions; Bem, 1972; Festinger, 1957). The nature and the effects of an attitude may depend on the basis by which it was formed.

Future research on the different schemas or bases for attitudes merits further attention. For example, attitudes can be activated from memory and triggered by cues related to the attitude object (Fazio, 1986, 1989; Sanbonmatsu \& Fazio, 1990). Attitudes can also be generated by direct experience with the attitude object (Fazio \& Zanna, 1978b; Regan \& Fazio, 1977; Songer-Nocks, 1976) or by affective feeling-based information generated by imagining an experience with an attitude object (Keller \& McGill, 1994; Pham, 1998; Schwartz, 1990). An attitude can also be based on group identification and social identity (Terry \& Hogg, 1996). If multiple schemas or bases can be used to form an attitude, people can form multiple evaluations of the same object depending on what they can or cannot retrieve about the object and, indeed, may even hold dual attitudes toward the same object 
(Wilson et. al., 2000). Therefore, future research should examine the complete set of mediating and moderating factors that increase the likelihood of forming an attitude using a particular basis for construction.

In our research, participants had relatively pallid direct experience and external information available to them (for control purposes). Readers may wonder the following: (a) How real are the attitudes generated in our studies? and (b) Will people actually rely on these attitudes to guide their behavior? These questions raise two issues that deserve attention in future research. Simply because an attitude is constructed does not automatically mean that it will be relied on to guide behavior. Therefore, future research should also consider the different processes by which a generated attitude is assessed as an appropriate guide for behavior. For example, Fazio and Towles-Schwen (1999) elaborated on Fazio's (1986) Motivation and Opportunity as Determinants (MODE) model. This framework suggests a direct and indirect path by which activated attitudes guide behavior. In the direct path, activated attitudes bias the subjective perceptions of the attitude object's qualities, and these qualities in turn guide behavior. Because a positive (negative) attitude makes the attitude object appear to have more positive (negative) qualities, and those positive (negative) qualities elicit positive (negative) behaviors, the direct route increases the likelihood of attitude consistent behavior. In the indirect route of the MODE model, activated attitudes (in conjunction with norms and behavioral control) produce intentions to act, leading to attitude behavior inconsistency if other inhibitory factors are not present (Schuette \& Fazio, 1995).

Finally, our research demonstrates an important point regarding the fluctuation and stability of attitudes and the consistency of attitudes, expression of attitudes, and behavior. In study 1 , processing goals and valence and order of information created variation in attitudes, begging the following question: Is there a true stable and consistent attitude when attitudes are constructed temporarily and subject to such influences? In contrast, study 2 illustrates how unwavering attitudes can be somewhat misleading-external contingencies can lead to conformity and an apparent consensus of evaluative responses (across participants), in contrast to attitudes expressed in the absence of such external contingencies.

\section{REFERENCES}

Bagozzi, Richard P., Henderson, Geraldine, Dabholkar, Pratibha A., \& lacobucci, Dawn. (1996). Network analyses of hierarchical cognitive connections between concrete and abstract goals: An application to consumer recycling attitudes and behaviors. In Dawn lacobucci (Ed.), Networks in marketing (pp. 367-383). Thousand Oaks, CA: Sage.

Bem, Daryl J. (1972). Self-perception theory. In Leonard Berkowitz (Ed.), Advances in experimental social psychology (pp. 1-62). San Diego, CA: Academic.

Bennet, William L. (1975). The political mind and the political environment. Lexington, MA: D.C.H.
Bettman, James R., Luce Mary Frances, \& Payne, John W. (1998). Constructive consumer choice process. Joumal of Consumer Research, 25. 187-217.

Bishop, George D. (1987). Experiments with the middle responce altemative in survey questions. Public Opinion Quarterly, 51, 220-232.

Bishop, George D., Hamilton, David L., \& McConahay, John B. (1980). Attitudes and nonattitudes in the belief systems of mass publics. Joumal of Social Psychology, 110, 53-64.

Burnkrant, Robert, \& Cousineau, Alain. (1975). Information and normative social influence in buyer behavior. Joumal of Consumer Research. 2 , 206-215.

Deutsch, Morton, \& Gerard, Harold. (1955). A study of normative and informational social influences upon individual judgment. Joumal of Abnormal Social Psychology, 51, 629-636.

Eagly, Alice H., \& Chaiken, Shelly. (1993). The psychology of attitudes. New York: Harcourt Brace.

Fazio, Russell H. (1986). How do attitudes guide behavior? In Richard M. Sorrentino \& Edward T. Higgins (Eds.), Handbook of motivation and cognition: Foundation of social behavior (pp. 204-243). New York: Guilfond.

Fazio, Russell H.(1989). On the power and functionality of attitudes: The role of attitude accessibility. In Anthony R. Pratkanis. Steven J. Breckler, \& Anthony G. Greenwald (Eds.), Attitude structure and function (pp. 153-179). Hillsdale, NJ: Lawrence Erlbaum Associates, Inc.

Fazio, Russell H., Chen, Jeaw-Mei, McDonel, Elizabeth C., \& Sherman, Steven, J. (1982). Attitude accessiblity, attitude-behavior consistency, and the strength of the object-evaluation assoication. Jourmal of Experimental Social Psychology, 18, 339-357.

Fazio, Russell H., \& Zanna, Mark P. (1978a). Attitudinal qualities relating to the strength of the attitude-behavior relationship. Jourmal of Experimental Social Psychology, 14, 398-408.

Fazio. Russell H., \& Zanna, Mark P. (1978b). On the predictive validity of attitudes: The roles of direct experience and confidence. Joumal of Personality, 46, 228-243.

Fazio, Russell H., \& Towles-Schwen, Tamara. (1999). The MODE model of attitude-behavior processes. In Shelly Chaiken \& Trope Yaacov (Eds.), Dual-process theories in social psychology (pp. 97-116). New York: Guilford.

Feldman, Jack, \& Lynch Jr., John G. (1988). Self-generated validity and other effects of measurement on belief, attitude, intention and behavior. Joumal of Applied Psychology. 73, 421-435.

Festinger, Leon. (1957). A theory of cognitive dissonance. Evanston, IL: Row, Peterson.

Fishbein, Martin, \& Ajzen, Icek. (1975). Belief, attitude, intention and behavior: An introduction to theory and research. Reading, MA: Addison-Wesley.

French, John R. P., \& Raven, Bertram. (1959). The bases of social power. In Dorwin Cartwright (Ed.), Studies in social power (pp. 150-167). Ann Arbor: University of Michigan Press.

Ha, Young-won, \& Hoch, Stephen J. (1989). Ambiguity, processing strategy, and advertising evidence interactions. Joumal of Consumer Research. 16, 354-360.

Hastie, Reid, \& Park, Bernadette. (1986). The relationship between memory and judgment depends on whether the judgement is memory-based or online. Psychological Review, 93, 258-268.

Hoch, Stephen J., \& Ha, Young-won. (1986). Consumer learning: Advertising and the ambiguity of product experience. Joumal of Consumer Research, 13, 221-233.

Huffman, Cynthia, \& Houston, Michael J. (1993). Goal-oriented experience and the development of knowledge. Joumal of Consumer Research, 20. 190-207.

Kaplan, Martin, \& Miller, Charles. (1987). Group decision making and normative versus informational influence: Effects of type of issue and assigned decision rule. Joumal of Personality and Social Psychology, 53. 306-313.

Katz, Daniel. (1960). The functional approach to the study of attitudes. Public Opinion Quarterly. 24.163-204. 
Keller, Punam A., \& McGill, Ann. (1994), Differences in the relative influence of product attributes under altemative processing conditions: Attribute importance versus attribute ease of imagability. Joumal of Consumer Psychology, 3, $29-49$.

Kelman, Herbert. (1961). Processes of opinion change. Public Opinion Quanterly, 25, 57-78.

King, Maryon F., \& Balasubramanian, Siva K. (1994). The effects of expertise, end goal, and product type on adoption of preference formation strategy. Journal of the Academy of Marketing Science, 22, 146-159.

Klinger, Eric. (1975). Consequences of commitment to and disengagement from incentives. Psychological Review, 82, 1-25.

Lassiter, Daniel G., Geers, Andrew L., Apple, Kevin J., \& Beers, Melissa J. (2000). Observational goals and behavior unitization: A reexamination. Joumal of Experimental Social Psychology, 36, 649-659.

Lerner, Jennifer S., \& Tetlock, Philip E. (1999). Accounting for the effects of accountability. Psychological Bulletin, 125, 255-275.

Lynch Jr., John G., \& Srull, Thomas K. (1982). Memory and attentional factors in consumer choice: Concepts and research methods. Joumal of Consumer Research, 9, 18-37.

Lynch Jr., John G., Marmorstein, Howard, \& Weigold, Michael F. (1988). Choices from sets including remembered brands: Use of recalled attributes and prior overall evaluations. Journal of Consumer Research. 15 . 169-184.

Park, C. Whan, \& Lessig, Parker V. (1977). Students and housewives: Differences in susceptibility to reference group influence. Joumal of Consumer Research, 4, 102-110.

Park, Jong-Won, \& Hastak, Manoj. (1994). Memory-based product judgments: Effects of involvement at encoding and retrieval. Journal of Consumer Reseurch, 21, 534-547.

Petemen, Michelle L. (1997). The effects of concrete and abstract consumer goals on information processing. Psychology \& Marketing, 14, 561-583.

Pham, Michel T. (1998). Representativeness, relevance, and the use of feelings in decision making. Journal of Consumer Research, 25, 144-159.

Regan, Dennis T., \& Fazio, Russell H. (1977). On the consistency between attitudes and behavior: Look to the method of attitude formation. Journal of Experimental Social Psychology, 13, 28-45.

Sanbonmatsu, David M., \& Fazio. Russell H. (1990). The role of attitudes in memory-based decision making. Joumal of Personality and Social Psychology, 59, 614-622.

Schuette, Robert A., \& Fazio, Russell H. (1995). Attitude Accessibility and motivation as determinants of biased processing: A test of MODE model. Personality \& Social Psychology Bulletin. 21. 704-710.

Schwartz, Shalom H. (1978). Temporal instability as a moderator of the attitude-behavior relationship. Journal of Personality and Social Psychology. 36. 715-724.

Schwarz, Norbert. (1990). Feelings as information: Informational and motivational functions of affective states. In Edward T. Higgins \& Richard M. Sorrentino (Eds.), Handbook of motivation and cognition: Foundation of social behavior (pp. 527-561). New York: Guilford.

Schwarz, Norbert. (200). Social judgment and attitudes: Warmer, more social, and less conscious. European Journal of Social Psychology. 30. 149-176.
Schwarz, Norbert, \& Bless, Herbert. (1992). Scandals and the public's trust in politicians: Assimilation and contrast effects. Personality \& Social Psychology Bulletin. 18, 574-579.

Schwarz, Norbert, \& Bohner, Gerd. (2000). The construction of uttitudes. Manuscript in preparation.

Shavitt. Sharon. (1990). The role of attitude objects in attitude functions. Journal of Experimental Social Psychology, 26, 124-148.

Smith, Brewster M., Bruner, Jerome S., \& White, Robert W. (1956). Opinions and personality. New York: Wiley.

Songer-Nocks, Elaine. (1976). Situational factors affecting the weighting of predictor components in the Fishbein model. Journal of Experimental Social Psycholngy, 12, 56-59.

Terry, Deborah J., Hogg. \& Michael A. (1996). Group norms and the attitude behavior relationship: A role for group identification. Personality and Social Psycholngy Bulletin, 22, 776-793.

Tesser, Abraham. (1978). Self-generated attitude change. In Leonard Berkowitz (Ed.), Advances in experimental social psychology (pp. 408-448). New York: Academic.

Tesser, Abraham, \& Leonard, Martin. (1996). The psychology of evaluation. In Edward T. Higgins \& Arie W. Kruglanski (Eds.), Social psychology: Handbook of basic principles (pp. 400-432). New York: Guilford.

Tetlock, Philip E., Skitka, Linda, \& Boettger, Richard. (1989). Social and cognitive strategies for coping with accountability: Conformity, complexity, and bolstering. Joumal of Personality and Social Psychology. $57,632-640$.

Tourangeau, Roger, \& Rasinski, Kenneth A. (1988). Cognitive processes underlying context effects in attitude measurement. Journal of Experimental Social Psychology. 25, 401-421.

Tversky, Amos, \& Kahneman, Daniel. (1974). Judgment under uncertainty: Heuristics and biases. Science, 185, 1124-1131.

Wilson, Timothy D., \& Hodges, Sara D. (1992). Attitudes as temporary constructions. In Leonard L. Martin \& Abraham Tesser (Eds.), The construction of social judgments (pp. 37-65). Hillsdale, NJ: Lawrence Erlbaum Associates, Inc.

Wilson, Timothy, Lindsey, Samuel, \& Schooler, Tonya Y. (2000). A model of dual attitudes. Psychological Review, 107, 101-126.

Wyer, Robert S., \& Hartwick, Jon. (1980). The role of information retrieval and conditional inference processes in belief formation and change. In Leonard Berkowitz (Ed.). Advances in experimental social psychology (pp. 241-284). Orlando, FL: Academic.

Zajonc, Robert B. (1968a), Attitudinal effects of mere exposure. Journal of Personality and Social Psychology, 9, 1-27.

Zanna, Mark P. (1990). Attitude functions: Is it related to attitude structure? Advances in Consumer Research. 17, 98-100.

Zanna, Mark P., \& Rempel, John K. (1988). Attitudes: A new look at an old concept. In Daniel Bar-Tal \& Arie W. Kruglanski (Eds.), The social psychology of knowledge (pp. 315-334). Cambridge, England: Cambridge University Press.

Accepted by Dawn Iacobucci. 